\title{
Method for Forecasting Electric Consumption for Household Users in the Conditions of the Republic of Tajikistan
}

\author{
Aleksandr Ivanovich Sidorov, Saidjon Sheralievich Tavarov* \\ Department of "Life Safety", South-Ural State University (National Research University), 454080, Lenin Avenue, 76, \\ Chelyabinsk, Russia
}

Corresponding Author Email: tabarovsaid@mail.ru

\section{https://doi.org/10.18280/ijsdp.150417}

Received: 15 February 2020

Accepted: 4 April 2020

\section{Keywords:}

electricity consumption, forecasting method, household consumers

\begin{abstract}
In the work, a method is proposed that allows predicting electricity consumption by household consumers in the terrain of the Republic of Tajikistan. To take into account the factor features of the terrain of the cities of the Republic of Tajikistan, a coefficient is proposed that characterizes the terrain conditions depending on the temperatures and the difference in the heights of the cities above the sea level. The adequacy of the proposed method for predicting electricity consumption by household consumers is presented in the form of dependences of annual electricity consumption schedules obtained by calculation and experimental methods.
\end{abstract}

\section{INTRODUCTION}

After the collapse of the Soviet Union and the independence of the Republic of Tajikistan, the dynamics of the power consumption of industrial enterprises in relation to household consumers began to decrease gradually.

This dynamics was influenced by a number of factors: the civil war, which led to a sharp decrease in funds for the reconstruction and modernization of existing electrical equipment, in particular in energy-intensive enterprises such as the Tajik Aluminum Plant, Tajik Textile Mach. Javanese
Chemical Plant, and. t.; shutdown of the supply of natural gas and the impossibility of transferring technological equipment from natural gas to electric energy due to increased electricity consumption by domestic consumers that has been grafted onto overloading existing electric networks. The increase in electricity consumption by household consumers in particular is due to the disconnection of heat and hot water supply, heating and natural gas and the transfer to full electrification, the structure of electricity consumption by years is shown in Figure 1.

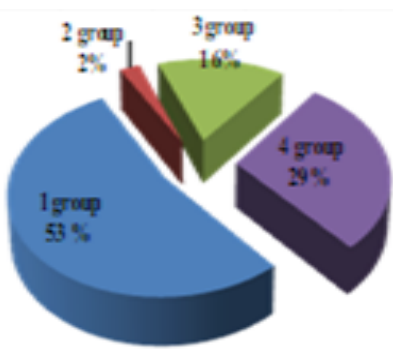

2010 Year

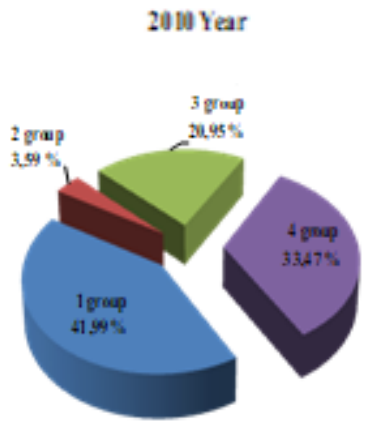

2013 Year

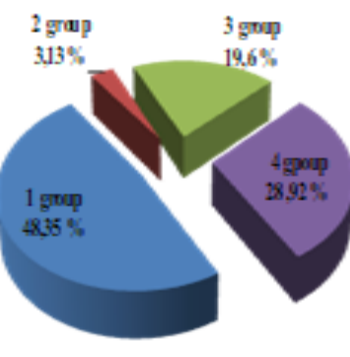

2011 Year

a)

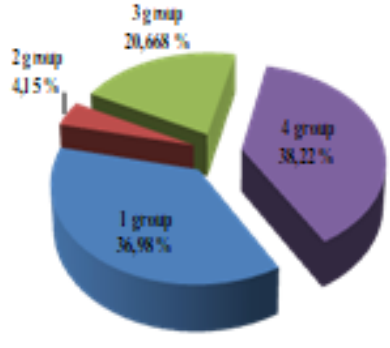

2014 Yex

b)

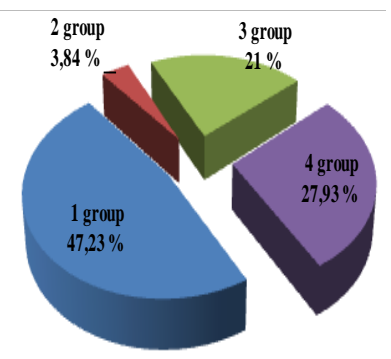

2012 Year

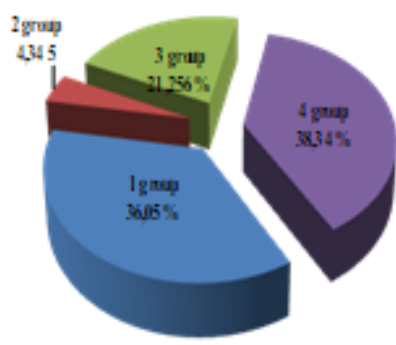

215 Year

Figure 1. Structure of power consumption by groups accepted in RT 
Group 1 - industrial, non-industrial, agricultural and equivalent consumers;

Group 2 - consumers of budgetary sphere, the enterprises of the communal services and electric transport;

Group 3 - pumping stations of machine irrigation systems, borehole and reclamation pumping stations;

Group 4 - population, localities, and dormitories.

According to Figure 1, the dynamics of electricity consumption by household consumers, as mentioned above, is increasing.

As you know, the dynamics of electricity consumption is affected by an increase in the population, as well as the number of people living in one apartment [1-17].

In the examined series of discounts, it is shown that the increase in power consumption is affected by the placement of people in rooms in the apartment [8-22]. Given the traditional feature of Central Asian countries, including the Republic of Tajikistan, an average of 4-6 people lives in one apartment.

Consequently, given the lack of heat and gas supply, hot water supply and heating to maintain optimal room temperatures (taking into account the number of people living in one apartment and the average use of at least two rooms), much more electricity is needed than jelly than in cases where household consumers are provided with other energy sources noted above

According to generally accepted opinions [6-10], the ambient temperature during the winter periods in Central Asian countries, including the Republic of Tajikistan, does not fall to critical values. However, this opinion does not fully correspond to reality, this is due to the fact that the terrain of the Republic of Tajikistan is quite complex.

The Republic of Tajikistan consists of $93 \%$ of the mountains, while altitudes vary from 2,000 to $7,500 \mathrm{~m}$ above sea level, such differences cannot affect the critical drops in ambient temperatures on winter days. Critical ambient temperatures during winter days are observed in particular in the North Eastern part of the Republic of Tajikistan, namely in the Sogd and Gorn-Badakhshan autonomous regions with the centers of the city of Hajent and the city of Khorog.

In this case, the following factor should be noted that according to the territorial arrangement, the ambient temperature of Dushanbe in winter does not fall below $-5^{\circ} \mathrm{C}$ and, for example, in the Gorno-Badakhshan Autonomous Region the ambient temperature in winter can reach $-30^{\circ} \mathrm{C}$ or more (there is no centralized heat supply), therefore, the time of using the maximum loads during the day in the GornoBadakhshan Autonomous Region will be significantly longer than in other regions of the country.

Therefore, I take into account the population growth, the tradition of children living with their parents, regardless of the age and the absence of other sources of energy, electricity consumption among household consumers will increase more and more.

It should be noted that the Republic of Tajikistan (RT) does not have its own regulatory documents and when determining electrical loads for the construction and reconstruction of urban electric networks, documents are used either developed in Soviet times or the Russian Federation.

\section{FORMULATION OF THE PROBLEM}

Setting the same specific load for the household sector according to ref. [21, 22] for the whole RT is not correct. It is well known that if the unit loads are incorrectly set and the power supply systems are designed according to these standards, there will be an increase in energy losses [6-23], and in the future, a reduction in the operating time of elements of power supply circuits.

The existing norms of specific loads for typical houses [21, 22], currently used in design, were developed during the Soviet Union and partly in modern Russia, they do not take into account the climatic and meteorological and territorial features of cities, as well as the load of air conditioners and electric water heaters.

The introduction of new specific load standards in the RT is complicated by a number of reasons, one of the main of which is the shortage of electricity production in winter.

Therefore, a relevant solution is the recommendation of energy consumption standards for cities of the Republic of Tajikistan based on the proposed forecasting method, but taking into account the climatic and meteorological and territorial features of the cities of the Republic of Tajikistan.

The reason for the shortage of electricity in the winter period is due to the fact that the main source of electricity in the Republic of Tajikistan is hydraulic power plants (HPPs), which account for more than $90 \%$ of the total electricity generated in the republic. At present, only one hydroelectric power station in the Republic of Tajikistan has its own reservoir (Nurek hydroelectric power station), while the rest are riverbed and depend on the influx of water due to the melting of glaciers.

Thus, in order to improve the quality of electricity and the reliability of electricity supply, it is necessary to develop a method for forecasting electricity consumption taking into account the current norms of specific loads and allowed capacity established by Barki Tajik for household consumers with typical houses, taking into account a number of factors affecting household electricity consumption .

These factors include the following: the territorial location of cities and climatic and meteorological conditions [6-22]. These factors affect the duration of the maximum load during the day and month [18-20].

\section{THEORETICAL PART}

In order to regulate the operational parameters of urban electric networks by the operational dispatching service, a method for forecasting power consumption for household consumers in the Republic of Tajikistan (RT) is proposed based on equations taking into account the maximum load time coefficient $\left(\alpha_{\text {maximum load time }}\right)$ obtained for various cities of the Republic of Tajikistan [19, 20] and having a functional relationship:

$$
\begin{gathered}
\alpha_{\text {maximum load time }}=f\left(x_{i}\right), \\
x_{i}=x_{1} ; x_{2} ; x_{3} ; x_{4} ; x_{5}
\end{gathered}
$$

where, $x_{1}$ - air temperature;

$x_{2}$ - features of the construction of houses;

$x_{3}$-height of cities above sea level;

$x_{4}$ - amount of precipitation;

$x_{5}$ - wind speed.

In view of the foregoing, we propose a method for predicting power consumption and average load for household 
consumers in the Republic of Tajikistan in the form of a system of equations taking into account factors - the coefficient of maximum load time $-\alpha_{\text {maximum load time }}$ for various cities of the Republic of Tajikistan [19, 20], which allows taking into account the territorial and climate meteorological feature of the Republic of Tatarstan.

The equations for forecasting power consumption and average power, taking into account the coefficient of time of maximum loads - $\alpha_{\text {maximum load time }}$ of the cities of the Republic of Tajikistan, are given below:

$$
\begin{gathered}
W_{\alpha_{\text {maximum load time }}+1}=W_{\text {consumption }} \\
\alpha_{\text {maximum load time }} \cdot\left(1-\alpha_{\text {maximum load time }}\right),
\end{gathered}
$$

$P_{\text {average time of maximum loads during the day }}$

$$
\begin{aligned}
& =\frac{W_{\alpha_{\text {maximum load time }}+1}}{t_{\text {maximum load time during the day }}} \\
& \cdot \alpha_{\text {maximum load times }}
\end{aligned}
$$

where, $W_{\text {consumption }}$ - electricity consumption during the period under review, $\mathrm{kW} \cdot \mathrm{h}$;

$t_{\text {maximum load time during the day }}$ - time of maximum loads during the day, hours,

$\alpha_{\text {maximum load time }}$ - time coefficient of maximum loads.

The coefficient that characterizes the terrain conditions ( $\left.\alpha_{\text {terrain conditions }}\right)$ is determined by the expression:

$$
\begin{aligned}
& \alpha_{\text {maximum load } t} \text {. } \\
& =\frac{\left(t_{\text {av. mon. am.tem. }}+t_{\text {tem.diff. }}\right)}{\left(t_{\text {av. mon. am. tem. }}+t_{\text {av.mon. add. tem. })}\right.}
\end{aligned}
$$

where: t(Ms. M. T.) - average monthly ambient temperature, ${ }^{\circ} \mathrm{C}$. (The value of the average environmental temperature is obtained according to "Tajikhydromet" for each month during the forecast period taking into account the location of points of elevation above sea level. In this paper, we consider the elevation points above sea level-2123 $\mathrm{m}$ for Khorog and $706 \mathrm{~m}$ for Dushanbe);

$t($ times. $t)$ - the temperature difference between the point at sea level and the point of location of the consumer above sea level, ${ }^{\circ} \mathrm{C}$. (the temperature Difference between the point at sea level and the points of location of the consumer above sea level) for the corresponding considered forecast months. For the consumer above sea level according to "Tajikhydromet" during the forecast period, and for a point at sea level for the same forecast periods according dateandtime.info. The need to take into account the temperature difference at these levels relative to the sea is due to the following.

When the altitude increases above sea level for every 100 meters, the average temperature decreases by $0.6^{\circ} \mathrm{C}$. Consequently, this leads to an increase in power consumption);

$\mathrm{t}(\mathrm{cf} . \mathrm{m}$. $\mathrm{t}$. $\mathrm{V} 0)$ - the average monthly temperature of the environment at the point at sea level, CC. (This value is the initial value for estimating the change in the average monthly temperature at the forecast point. It is selected based on data dateandtime.info);

$\mathrm{t}(\mathrm{cf}$.).)- average monthly additional temperature, CC. (This average monthly temperature characterizes the degree of constructability of residential buildings, taking into account the thermal insulation ability, and shows the difference between the average monthly temperature of the external and internal temperature of a residential building [18-25]. As noted above, due to the lack of heating in the winter in the cities of the Republic of Tajikistan, for well-known reasons, the temperature inside a residential building is much lower than in houses with heating. Therefore, the average monthly additional temperature in (4) at sub-zero average monthly temperatures when predicting power consumption for household consumers can be taken into account if the factors listed above are taken into account. But at the same time, to choose thermal insulation materials for construction, it is necessary to focus on the fact that in summer the temperature in the Central and southern cities of the Republic of Tajikistan can reach $+40-45^{\circ} \mathrm{C}$ ).

The obtained equations will allow us to predict, plan and control power consumption $[19,20]$ without violating the established norms of specific loads. To maintain those operating parameters in the power supply system, it is necessary to develop power consumption standards that do not exceed specific loads [21, 22].

\section{PRACTICAL PART}

Based on the obtained Eq. (3) for the considered cities of the Republic of Tajikistan, taking into account the climatic and meteorological conditions of the terrain and the territoriality of their location, we recommend the following standards for electricity consumption by household consumers. In our opinion, these recommended norms will allow us to solve the previously set tasks, thereby improving the reliability of power supply and all indicators that affect the reliability of power supply, in particular, in $0.4 \mathrm{kV}$ networks. We will present the results of the recommended energy consumption standards in the form of recommended average electricity consumption schedules for 52 household consumers located in the east and central part of Tajikistan (Figure 2 and Figure 3).

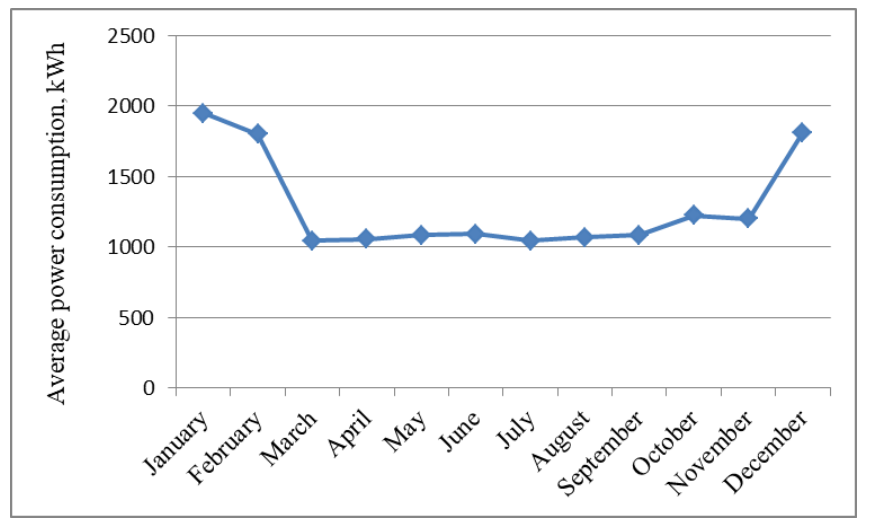

Figure 2. Recommended average power consumption schedule for 52 household consumers located in Eastern Tajikistan

To verify the adequacy of the recommended average power consumption schedules (Figure 2 and Figure 3) obtained on the basis of the proposed forecasting method (Eq. (3)), we determine the average loads at peak hours during the considered period. The results of the calculations are presented in table.

The given values of average loads at maximum hours in the table. correspond to the values established for household consumers according to $[21,22]$. 
Table 1. Average loads during peak load hours

\begin{tabular}{|c|c|c|c|c|c|c|c|c|c|c|c|c|}
\hline Name & January & February & March & April & May & June & July & August & September & October & November & December \\
\hline $\begin{array}{c}\text { Average } \\
\text { power } \\
\text { consumption, } \\
\mathbf{k W h} \\
\text { (Eastern } \\
\text { cities) }\end{array}$ & 1947.9 & 1797.8 & 1044.1 & 1056.3 & 1082.4 & 1089.9 & 1043.5 & 1067.7 & 1083.0 & 1224.8 & 1200.2 & 1812.9 \\
\hline $\begin{array}{c}\text { Average } \\
\text { power } \\
\text { consumption, } \\
\mathbf{k W h} \\
\text { (Central } \\
\text { cities) }\end{array}$ & 1662.9 & 1624.9 & 1459.6 & 1430.1 & 1402.4 & 1350.0 & 1280.3 & 1353.7 & 1415.7 & 1541.6 & 1696.2 & 1728.4 \\
\hline $\begin{array}{l}\text { The average } \\
\text { load, kW } \\
\text { (East of the } \\
\text { city) }\end{array}$ & 6.8 & 6.3 & 3.6 & 3.7 & 3.8 & 3.8 & 3.695767 & 3.7 & 3.8 & 4.3 & 4.2 & 6.4 \\
\hline $\begin{array}{c}\text { Average } \\
\text { load, kW } \\
\text { (Central } \\
\text { cities) }\end{array}$ & 4.3 & 4.2 & 3.8 & 3.7 & 3.6 & 3.5 & 3.361045 & 3.5 & 3.7 & 4.0 & 4.4 & 4.5 \\
\hline
\end{tabular}

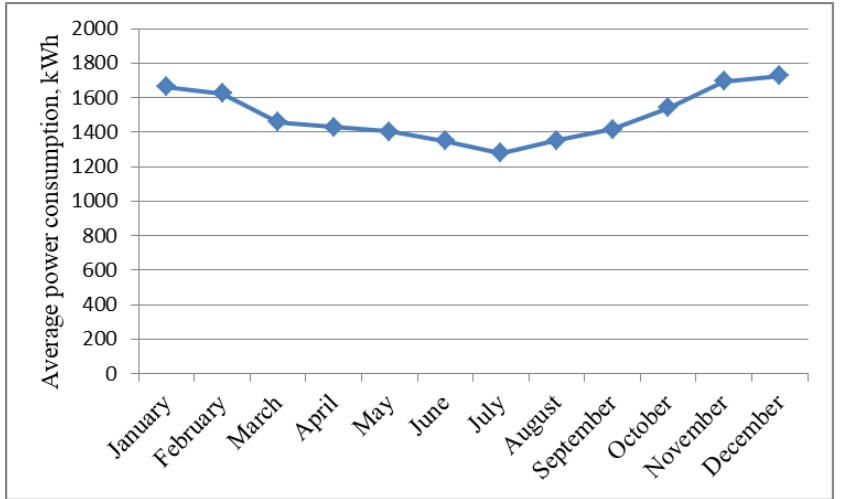

Figure 3. Recommended average power consumption schedule for 52 household consumers located in the Central part of Tajikistan

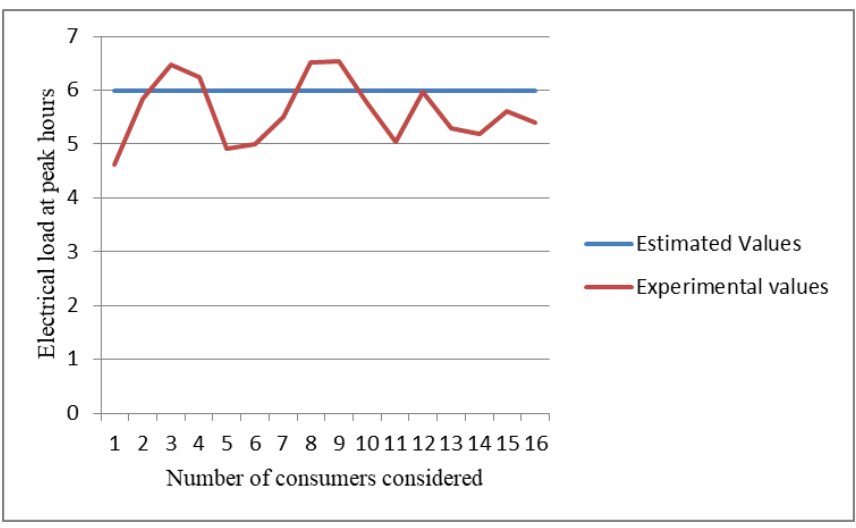

Figure 4. Comparison of calculated and experimental values of average electric load at maximum hours for 16 consumers (eastern cities of Tajikistan)

Given that the maximum power consumption is observed on winter days, therefore, at this time, the average load increases. To assess the results obtained (see Table 1), we construct the dependences of the average electric load at maximum hours for 16 household consumers Figures 4-6. For a constant value, we take the normalized value set in accordance with [21, 22].

The given dependences (see Figures 4-6) once again show that during the day the electrical load of household consumers does not change uniformly. The results obtained by calculation allow us to correctly predict the electrical load, and thereby taking into account the above that more than $90 \%$ of the generated electricity is on the balance of the hydraulic stations, and for these types of power plants, the possibility of prepredicted power consumption allows more efficient and reliable generation of electricity.

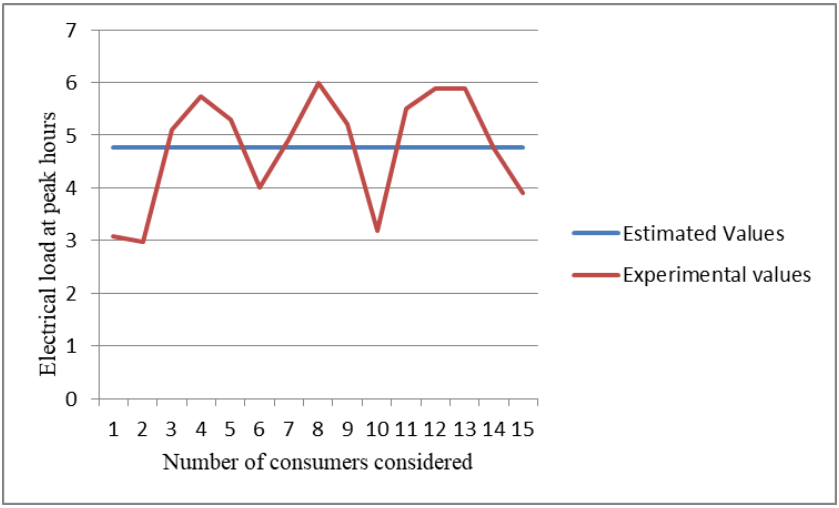

Figure 5. Comparison of calculated and experimental values of the average electric load at maximum hours for 16 consumers (capital of Tajikistan)

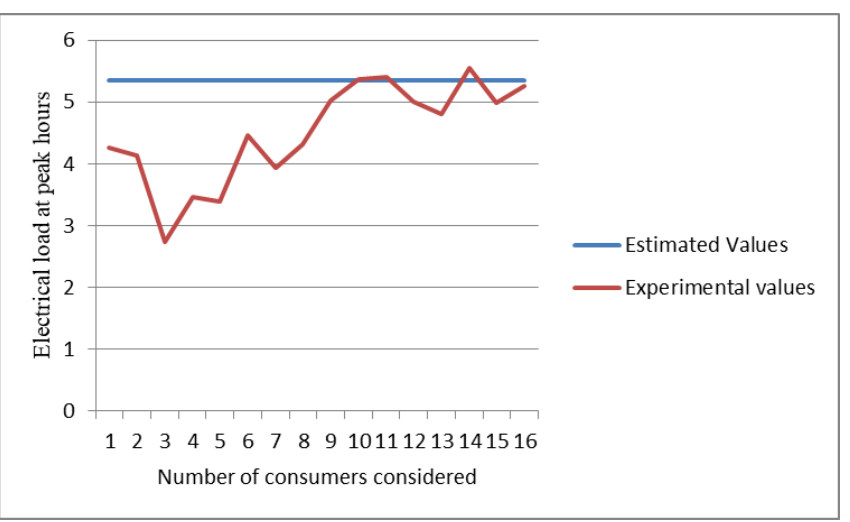

Figure 6. Comparison of calculated and experimental values of average electric load at maximum hours for 16 consumers (northern cities of Tajikistan) 


\section{DISCUSSION OF RESEARCH RESULTS}

The obtained method of forecasting power consumption by household consumers, taking into account all factor conditions, allows us to solve the tasks set from the beginning. The main task of this article was to obtain a method for forecasting power consumption, which would take into account the influence of changes in climatic and meteorological conditions of the locality of the cities under consideration, and would also allow without changing the established specific norms of electrical loads [21, 22] for the proposed average power consumption by household consumers (see Table 1) plan and control modes of operation of urban electric networks.

Using the derived Eq. (3) and the coefficient of maximum load time taking into account the terrain conditions of the Republic of Tajikistan, the average values of power consumption by household consumers were obtained and recommended for the first time.

The given data of average calculated capacities during peak load hours (see Table 1) depending on the recommended average values of power consumption by household consumers do not permissible values [21,22]. At the same time, it should be noted that the proposed forecasting method allows you to equalize the average load, thereby reducing the under loading mode during the summer hours of maximum loads, thereby optimizing the network operation mode.

\section{CONCLUSIONS}

1. A method is Proposed that allows predicting power consumption by household consumers in the conditions of the RT area.

2. The dependence of changes in height differences on power consumption by household consumers is established. This dependence is presented as a coefficient that characterizes the terrain conditions of the cities of the Republic of Tajikistan.

3. The Adequacy of the proposed method for predicting power consumption by household consumers is shown in the form of a comparison of the results obtained by calculation and experimental methods.

\section{REFERENCES}

[1] Zakaria, Y., Anup, P. (2018). An optimal load schedule of household appliances with leveled load profile and consumer's preferences. 2018 International Conference on the Domestic Use of Energy (DUE), Cape Town, South Africa, pp. 1-7. https://doi.org/10.23919/DUE.2018.8384382

[2] Zakaria, Y., Pule, K.H. (2018). A binary integer programming model for optimal load scheduling of household appliances with consumer's preferences. 2018 International Conference on the Domestic Use of Energy (DUE). Cape Town, South Africa, pp. 1-8. https://doi.org/10.23919/DUE.2018.8384381

[3] Gheorghe, G., Florina, S. (2015). Processing of smart meters data for peak load estimation of consumers. $9^{\text {th }}$ International Symposium on Advanced Topics in Electrical Engineering (ATEE). Bucharest, Romania, pp. 864-867. https://doi.org/10.1109/ATEE.2015.7133922

[4] Hussein, S., Boonruang, M. (2018). Intelligent algorithm for optimal load management in smart home appliance scheduling in distribution system. 2018 International Electrical Engineering Congress (iEECON), Krabi, Thailand, Thailand, pp. 1-4. https://doi.org/10.1109/IEECON.2018.8712166

[5] Jangkyum, K., Han, J., Kim, N., Kim, M, Choi, J. (2018). Analysis of power usage at household and proper energy management. 2018 International Conference on Information and Communication Technology Convergence (ICTC). Jeju, South Korea, pp. 450-456. https://doi.org/10.1109/ICTC.2018.8539459

[6] Makokluev, B.I., Kostikov, V. (1994). Modeling of electric loads of electric power systems. Electricity, 10: 6-18.

[7] Makokluev, B.I., Pavlikov, V., Vladimirov, A. (2003). Influence of fluctuations of meteorological factors on power consumption of power units. Powerman, 6: 11-23.

[8] Makokluev, B.I. (2019). Trend of electricity consumption of UES of Russia. Scientific and Technical Journal "Energy of the Unified Network", 5(48): 56-64. https://www.xn-----glcfccctdci4bhow0as6psb.xn-p1ai/publications/103-5-48-2019-g/288-tendentsiielektropotrebleniya-energosistem-rossii-trends-inpower-consumption-of-russia-s-power-grid-system.

[9] Makokluev, B.I., Polizharov, A.S., Basov, A.A., Alla Yu, E., Loktionov, S.V. (2018). Short-term forecasting of power consumption of power systems. Electric Stations, 4: 24-35.

[10] Makokluev, B.I., Polizharov, A.S., Antonov, A.V., Govorun, M.N., Kolesnikov, A.V., Basov, A.A., Alla Yu, E. (2019). Operational correction of schedules of electric power consumption in the planning cycle of the balancing market. Electric Stations, 5: 36-44.

[11] Repkina, N.G. (2015). Study of factors affecting the accuracy of daily power consumption forecasting. News of higher educational institutions. Electromechanics, 2: 41-43. http://dx.doi.org/10.17213/0136-3360-2015-241-43

[12] Zubakin, V.A., Kovshov, N.M. (2015). Methods and models for analyzing the volatility of electricity consumption taking into account cyclicality and stochasticity. Analysis, Forecast, and Management, 7(15): 6-12.

[13] Komornik, S., Kalichets, E. (2008). Requirements for energy consumption forecasting systems. Energo. Market, 3: 5-7.

[14] Vorotnitsky, V.E., Morzhin Yu, I. (2018). Digital transformation of energy in Russia -a system task of the fourth industrial revolution. Scientific and Technical Journal "Energy of the Unified Network", 6(42): 12-21.

[15] Vorotnitsky, V.E. (2018). The Solution to the problems of the Russian electric power industry should be systematic, qualified and customer-oriented. Powerman, 6: 14-21.

[16] Vorotnitsky, V.E. (2019). On digitalization in the economy and electric power industry. Powerman, 12: 614.

[17] Valeev, G.S., Dzyuba, M.A., Valeev, R.G. (2016). Modeling of daily load schedules of 6-10 kV distribution network sections in cities and localities under conditions of limited initial information. Bulletin Of SUSU. A Series of "Energy", 16(2): 23-29. https://doi.org/10.14529/power160203

[18] Sidorov, A.I., Khanzhina, O.A., Tavarov, S.S. (2019). 
Ensuring the efficiency of distribution networks C. Dushanbe and Republic of Tajikistan. International Multi-Conference on Industrial Engineering and Modern Technologies (FarEastCon), Vladivostok, Russia, pp. 14. https://doi.org/10.1109/FarEastCon.2019.8934377

[19] Sidorov, A.I., Tavarov, S.S. (2019). Normalization of power consumption in the Republic of Tajikistan taking into account the climatic features of the region. Scientific and Technical Journal "Energy of the Unified Network", 3(45): 70-75.

[20] Tavarov S.S. (2019). Specific power consumption of the domestic sector taking into account the ambient air temperature and the territorial location of the Republic of Tajikistan. Industrial Power Engineering, 7(7): 19-22.

[21] SP 256. 1325800.2016. Electrical installations of residential and public buildings rules of design and installation [Electronic resource]. URL: http://files.stroyinf.ru/Data2/1/4293751/4293751598.ht m, accessed on Jul. 11, 2017.

[22] RM-2696-01. Temporary instructions for calculating electrical loads of residential buildings. Moscow. Publishing house GUP "NIAC". 2001. 22 p.

[23] Vatin, N.I., Gorshkov, A.S., Nemova, D.V. (2013). Energy efficiency of enclosing structures during major repairs. Construction of Unique Buildings and Structures, 3(8): 1-10.

[24] GOST 30494-2011. Residential and public buildings. The parameters of the microclimate in the premises.

[25] Boguslavsky, L.D. (1985). Reducing energy consumption when working with heating and ventilation systems. Moscow, Stroizdat, 336 pages. 